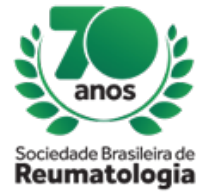

\title{
PSORIATIC ARTHRITS WITHOUT CUTANEOUS INVOLVEMENT - CASE REPORT
}

Giovana Dutra Saquy (Universidade Federal de Sergipe, Aracaju, SE, Brasil), Luiza Todt Cardoso Faro (Universidade Federal de Sergipe, Aracaju, SE, Brasil), Thiago Reis Santana (Universidade Federal de Sergipe, Aracaju, SE, Brasil), Regina Adalva Lucena Couto Ocea (Universidade Federal de Sergipe, Aracaju, SE, Brasil), Telma Rodrigues Santos Paixão (Universidade Federal de Sergipe, Aracaju, SE, Brasil), José Caetano Macieira (Universidade Federal de Sergipe, Aracaju, SE, Brasil), Lina Oliveira Carvalho (Universidade Federal de Sergipe, Aracaju, SE, Brasil), Blenda Hilíria Sousa Dias (Universidade Federal de Sergipe, Aracaju, SE, Brasil), Mônica Valéria Siqueira Santana Vechi (Universidade Federal de Sergipe, Aracaju, SE, Brasil)

\section{BACKGROUND}

Psoriatic arthritis is a chronic inflammatory disease, immunomediated, characterized by predominantly cutaneous and articular involvement. Joint disease usually manifests after a long time of cutaneous involvement. About $10 \%$ of the patients may evolve with osteoarticular manifestations prior to the psoriasiform presentation. The erosive and polyarticular form is rare, usually associated with dactylitis.

\section{CASE REPORT}

Patient, 32 years old, female, presented with symmetric additive polyarthritis of small joints, mainly metacarpophalangeal (MCFs), proximal interphalangeal (IFPs) and distal interphalangeal (IFDs), ankles and knees, as well as dactylitis and calcaneus enthesopathy 4 years ago. There was no cutaneous involvement or clinical complaints in the axial region during the follow-up. Laboratory tests showed a negative rheumatoid factor, FAN reagente, 1: 640 fine dotted nuclear. Radiographs of hands and wrists showed a diffuse reduction of intercapal and radiocarpal spaces, erosion in distal interphalangeal, compatible with "pencil in cup" deformities, lumbar spine radiographs and pelvis without alterations. Initiated treatment with Methotrexate, Leflunomide and corticoid for six months without satisfactory response. Subsequently, we chose to introduce Secuquinumab due to the important peripheral and enthesal involvement, with good clinical response and reduction of the composite index of disease activity (DAS28).

\section{CONCLUSION}

We emphasize the serious and early evolution peripheral osteoarticular injury in the patient, even without nail and cutaneous involvement. 